IJMS 2017 vol. 4 (2): 49 - 54

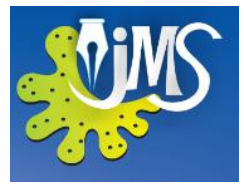

\title{
Seismic Activity near the Sunda and Andaman Trenches in the Sumatra Subduction Zone
}

\author{
Gamage SSN \\ Department of Physics, Faculty of Applied Sciences, University of Sri Jayewardenepura, \\ Nugegoda, Sri Lanka
}

\begin{abstract}
Subduction zones are generally characterized by well-defined inclined seismic zones extending, in some cases, down to about $670 \mathrm{~km}$ deep beneath the Earth. The Sumatra subduction zone is characterized by the IndoAustralia Plate subducting beneath the Sunda plate and Andaman micro plate about $55 \mathrm{~mm} / \mathrm{yr}$, causing seismic activity along the plate boundary. Seismic activity of the shallow part of Sumatra subduction zone near the Sunda and Andaman trenches and outer-rise region was analyzed by using earthquake locations and their focal mechanisms to study the seismic tectonic of the region. The study region was divided into five sub-regions and in each sub region, the focal mechanisms were analyzed according to the depth variation of bathymetry. The distribution of pressure axes, Tensional axes and Null axes of focal mechanisms were investigated. The results of the study can be concluded as given below. Present study shows that normal faulting events are recorded than the reverse faulting events in the outer-rise region. In the near trench of the region, reverse faulting events were observed more than the normal faulting events and more reverse faulting events were observed in the shallow part of the trench. Although only the focal mechanism solutions of large events were used for the analysis which may have location errors, the present study results reasonably agree with the results obtained by the other subduction zones. Patterns of hypocenter distribution and focal mechanisms found in this study are almost the same as that found under the near-trench slopes of other subduction zones by previous investigators. This characteristics of focal mechanisms may be due to the bending of the subdcting plate near the Sunda and Andaman Trenches.
\end{abstract}

KEYWORDS: Seismicity and tectonics, Indo-Australia plate, Sumatra subduction zone, Intra plate process, offshore Sri Lanka

Corresponding author: Shantha S.N. Gamage, Email: sng@sjp.ac.lk 


\section{INTRODUCTION}

Subduction zones are down going limbs of the mantle convection system, where the cold oceanic plates formed at mid-ocean ridges return to the deep mantle (Stein and Wiens, 1986). The subduction zones are generally characterized by the inclined seismic zones extending, in some cases, down to about $700 \mathrm{~km}$ deep beneath the Earth that is Wadati-Benioff zones.

Kiyoo Wadati proved the existence of deep earthquakes and discovered inclined seismic zone in Japan dipping westward from the Pacific Ocean with iso-depth contours paralleling the Japan arcs (Wadathi-Benioff zone - WBZ) in 1935. This discovery has been playing an important role in better understanding the hypothesis of the plate tectonics and the subduction process. Since this discovery, many seismologists have been developing the idea for better understanding of subduction processes by using various types of investigations.

The geometry of the subducting plate is usually identified with the geometry of the corresponding Wadathi-Benioff zone. Different subduction zones have different features associated with their geological phenomena. These phenomena are mostly controlled by the origin of the plate, path of the plate that passed before its subduction, age of the plate, and temperature structure of the plate and surrounding mantle. All the subduction zones have not been equally studied; the knowledge about their seismological and geophysical phenomena is limited. Therefore most of the ideas have developed based on the results of well-studied subduction zones.

Double-planed deep seismic zones are one of the well-studied zones in WBZs. The double-planed deep seismic zone was first discovered in the NE Japan subduction zone (Umino and Hasegawa, 1975; Hasegawa et al., 1978). Since this discovery, double-planed deep seismic zones have been identified in many other subduction zones in the world such as Central Aleutians, northern Chile, Kamchatka, Kuriles, New Britain, Tonga, Cape Mendocino, Alaska, NE Taiwan and New Zealand. Each double-planed deep seismic zone has different features. These double-planed deep seismic zones have been most successfully discovered in regions where local seismic networks provide appropriate coverage to yield high-precision hypocenters of earthquakes.

Previous researches on the seismic structures of numerous subduction zones have shown that earthquakes which occurred near trenches usually have shallow focal depths. Engdahl and Billington (1986) revealed earthquakes which occur near the central Aleutian Trench have focal depths shallower than about $45 \mathrm{~km}$. Further, Yoshii (1979) and Nishizawa et al. (1992) indicated that earthquakes which were located near the Japan Trench in the NE Japan subduction zone have focal depth shallower than $20 \mathrm{~km}$. The double seismic zone was first determined by NE Japan subduction zone. (Umino and Hasegawa 1975).

\subsection{Seismic activity of Sumatra subduction zone}

The subduction zone of Sumatra is described by the Indo-Australia Plate subducting beneath the Sunda plate and Andaman micro plate about 55 $\mathrm{mm} / \mathrm{yr}$, causing seismic activity along the plate boundary (De Mets et al., 2005). Therefore a large number of earthquakes take place in the region. Sumatra is an island in western Indonesia. The Sunda arc, extending over 5,600 $\mathrm{km}$ from the Andaman Islands in the northwest to the Banda arc in the east, was formed by the convergence between the Indo-Australian and Eurasian plates.

The Sumatra subduction zone is situated within the Sunda arc. Generally there are two zones of tectonic features that affected Sumatra Island. Those are subduction zones and transform fault zones. All of the earthquakes which occur near convergent boundaries where an oceanic plate is being subducted under a continent or an island 
arc are classified as subduction zones. The other classification is transform zone which is a terminology for earthquakes that occurred on the boundary between two lithospheric plates which are sliding past one another.

Sumatra subduction zone is known as one of the most active plate tectonic boundaries in the world. Numerous large earthquakes have happened in the Sumatra subduction zone within last two centuries. These events were included in the year 1833 with a magnitude of 8.8-9.2, in the year 1861 with a magnitude of 8.3-8.5, in the year 2004 with a magnitude of 9.0-9.3 and in 2005 with a magnitude of 8.7 .

There had been five major earthquakes of magnitude greater than 8.0 in this region from 2000 to 2014. Those five were recorded on 26th December 2004, 28th March 2005, 12th September 2007, and two on 11th April 2012 (Figure 1). The Magnitude 9.0-9.3 SumatraAndaman earthquake of 26 December 2004, the most severe among the top nine earth-quakes reported during the last two centuries.

The geometry of faulting during earthquake fault slip is denoted by focal mechanism solutions. Spatial distribution of focal mechanisms will give us information about earthquake generating stresses in and around the focal area. Information on stress distribution in the study region would improve the understanding of seismotectonics in the region. The main purpose of this study is to analyze the seismic activity of the shallow part of Sumatra subduction zone near the trench and outer-rise region (Figure 1). For this purpose, the offshore earthquake locations and their focal mechanism solutions were analyzed.

\section{DATA AND METHODOLOGY}

Hypocenter data obtained from the Data Management Center (DMC) at the Incorporated Research Institutions for Seismology (IRIS) were used for this study. With related to the studying scope all the necessary data from January 1964 to April 2011 were used having the latitude between $15 \mathrm{~N}$ and $-12 \mathrm{~S}$, longitude between $88 \mathrm{E}$ and $110 \mathrm{E}$ along with depths ranging 0 to $700 \mathrm{~km}$ in all the magnitude range. Focal mechanism solutions data in the same region were obtained from the Harvard CMT catalog for the earthquakes of magnitude greater than 3.5 occurring from 1976 to 2011 (Figure 2).

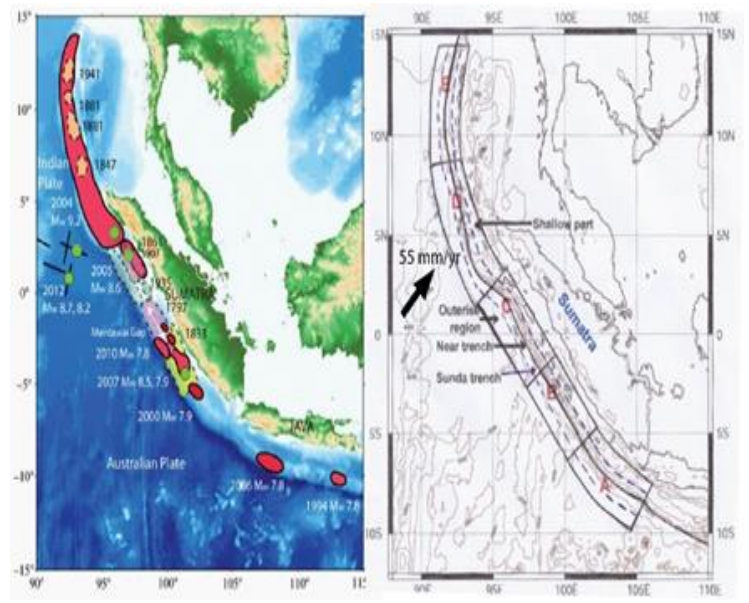

Figure 1: The map showing the study region. Left: Rupture areas of large earthquakes took place in the Sumatra subduction zone. Closed areas show the re-ruptured regions and dashed areas show the seismicity gaps. Right: Outerrise, near trench and shallow part in the study region and sub-regions $\mathrm{A}, \mathrm{B}, \mathrm{C}, \mathrm{D}$ and $\mathrm{E}$.

The focal mechanism solutions of outer-rise, near trench and shallow part near the Sunda and Andaman trench region were analyzed by dividing the region into five sub-regions according to the depth variation of bathymetry (Figure 1). For analyzing focal mechanism, two methods were used and first a graphical method was employed.

Topographic, bathymetric and focal mechanism solutions data were combined and maps were plotted for studying time period, for each year separately. Map of all the focal mechanism solutions is given in the Figure 2. Average focal mechanism solution for all the events were analyzed using fault plane solutions. 


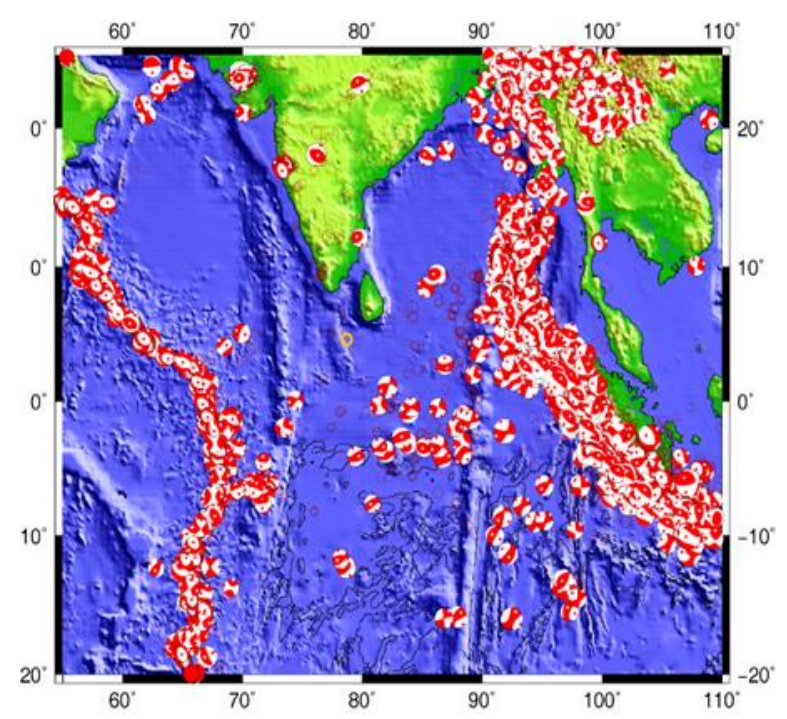

Figure 2: Focal mechanism solutions data in the offshore Sri Lanka obtained from the Global Centroid Moment Tensor database, catalog for the earthquakes of magnitude greater than 3.5 occurring from 1976 to 2011.

\section{RESULTS AND DISCUSSION}

When analyzing the focal mechanism solutions prior to the Sumatra-Andaman earthquake of $26^{\text {th }}$ December 2004, all the earthquake that occurred in the outer-rise region of the part A, were found as normal faults. Also considering about the earthquakes that occurred in the near trench, $81 \%$ of them were reverse faults and $19 \%$ of them were normal faults. Highest percentage of the earthquakes in shallow part contained fault geometry which was reverse faults and few of them were strike slip faults. With considering to the part B, normal and reverse faults were observed in equal percentages of the outer-rise region. Fault geometry of all events in the near trench was reverse and highest percentage of the events in shallow part was observed to be reverse as well. Neither strike fault was observed in part B.

In part $\mathrm{C}$, no earthquakes were reported in the outer-rise region. There were more reverse faults than the normal faults in near trench. But comparing normal faults of near trench and shallow part, normal faults in near trench were higher than that was observed in the shallow part. Highest percentage of the events in shallow part contained fault geometry which was reverse. Considering the part D, number of normal, reverse and strike faults was same in the outerrise region and most of the earthquakes observed in the shallow part and the near trench were reverse faults. In Part E, no events were reported in the outer-rise region and all the earthquakes were reverse faults in the near trench. Out of earthquakes occurred in the shallow part, $54.6 \%$ of them were recorded as reverse faults and others were normal faults.

Generally, many aftershocks are supposed to be occurring in the nearby regions after a major shock being taken place. These aftershocks can be appeared either in a few weeks or even in several years later (Gamage et al., 2009). Therefore analysis was also done taking data before and after the occurrence of the 2004 Sumatra earthquake. According to the analysis; normal faults were recorded more than the reverse faults in the outer rise region. Fault geometry of earthquakes in the shallow part of the trench was normal than reverse faults (See Figure $3 \& 4$ ). But in near trench of the region, reverse faults were observed more than the normal faults were, this was not agreeable with theoretical observations. When considering before the $26^{\text {th }}$ December 2004 Sumatra earthquake, percentage of the normal faults in near trench has increased than before the earthquake.

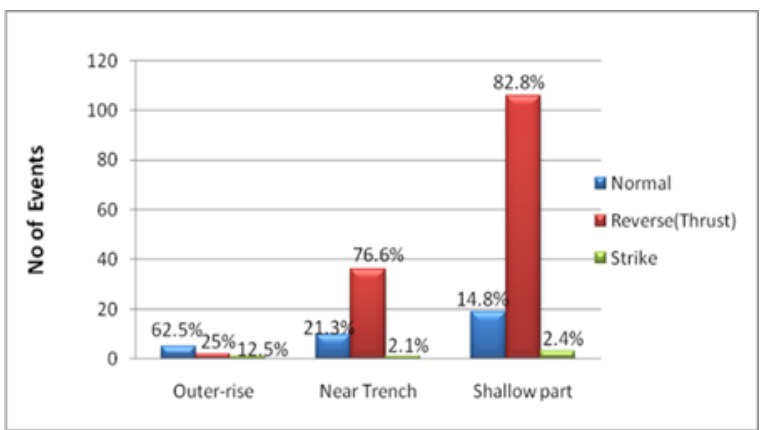

Figure 3: Distribution of number of events in faults with respect to the regions, outer-rise, near 
trench and shallow part for before the $26^{\text {th }}$ December 2004 Sumatra earthquake. Colours are associated in such a way that, blue represents normal faults, red represents reverse (thrust) faults and green represents strike faults. Percentage values relevant to each region with contribution of faults are shown top of the each bar.

Pressure axes, Tensional axes and Null axes of earthquake faults were plotted and the distribution of the focal mechanisms were analyzed by the method described by Gamage et al. (2009). The results are shown in the Figure 5. Our analysis shows that normal faults are recorded than the reverse faults in the outer rise region. In the near trench of the region, reverse faults were observed more than the normal faults and more reverse faults were observed in the shallow part of the trench.

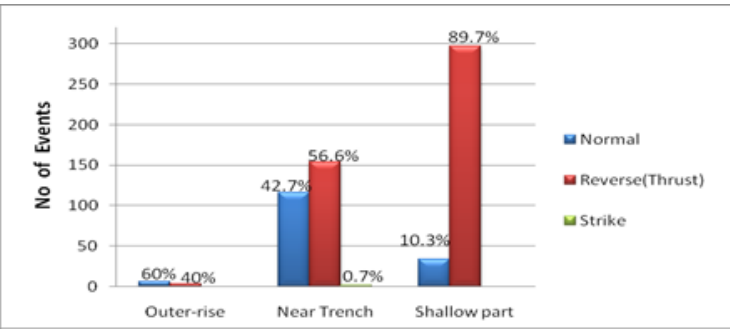

Figure 4: Distribution of number of events in faults with respect to the regions, outer-rise, near trench and shallow part for after the $26^{\text {th }}$ December 2004 Sumatra earthquake. Colours are associated in such a way that, blue represents normal faults, red represents reverse (thrust) faults and green represents strike faults. Percentage values relevant to each region with the contribution of faults are shown top of the each bar.

The typical focal mechanisms of near trench and outer-rise are reverse fault types and normal fault types, respectively. In order to account for the distribution of focal mechanisms obtained in the present study, a plate bending model at the trench can be used. The cold Indo-Australia Plate, which has traveled a large distance from the ridge, starts to subduct at the Andaman and
Sunda trench by downward flexure. This bending due to the downward flexure may lead to the earthquake-generating stresses in the plate near the trench.

For this analysis Harvard CMT catalog data were used. They recorded only high magnitude earthquakes over the period from 1976 till present. But the estimators involved with them are more likely to be erroneous. Therefore the results of this analysis part cannot expect to be accurate hundred percent. The data obtained from various international networks are having multiple errors such as epicentral errors, focal depth errors and magnitude errors. The errors associated with the data were assumed to be negligible in terms of their influences on this analysis.

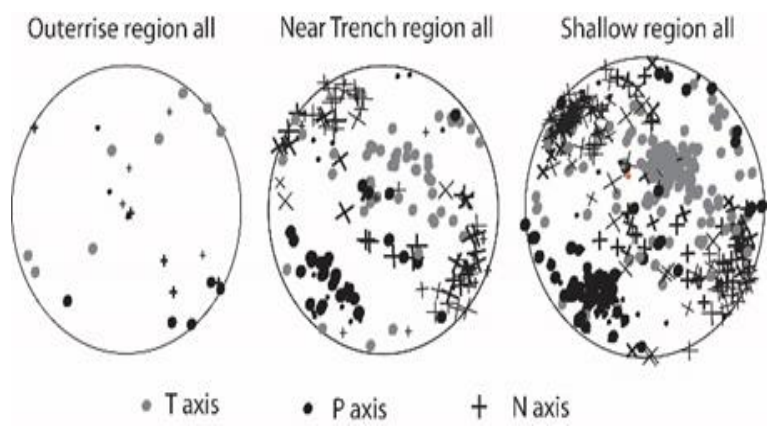

Figure 5: Distribution of the $\mathrm{P}, \mathrm{T}$ and Null axes of focal mechanisms for events studied in the present study. Left, center and right figures are mechanisms related to outer rise, near trench and shallow earthquakes respectively. The location of each axis is projected on a lower focal hemisphere using an equal area projection. Black circles, grey circles and plus symbols denote $\mathrm{P}, \mathrm{T}$ and Null axes, respectively.

\section{CONCLUSIONS}

The seismic activity of the shallow part of Sumatra subduction zone near the trench and outer-rise region were analyzed by using earthquake locations and their focal mechanism solutions. The results of the study can be concluded as given below. 
The analysis results show that normal faults are recorded than those of the reverse faults in the outer rise region. In the near trench of the region, reverse faults were observed more than the normal faults and more reverse faults were observed in the shallow part of the trench. Although we only analyze the focal mechanism solutions of large events, our results agree with the results obtained those of the other subduction zones.

This hypocentre distribution pattern and focal mechanisms identified in the present study are the same as that found under the outerrise/outer-trench slopes of subduction zones by previous investigators (Stauder, 1968; Chapple and Forsyth 1979; Gamage et al., 2009). The characteristics of focal mechanisms identified in the present study for the shallow seismic zone near the trench region may be explained by the bending-unbending model of the subducting zone.

\section{REFERENCES}

CHAPPLE W \& FORSYTH D. Earthquakes and bending of plates at trenches, J. Geophys. Res. 1979; 84: 6729-6749.

ENGDAHL ER \& BILLINGTON S. Focal depth determination of central Aleutian earthquakes, Bull. Seism. Soc. Am. 1986; 76: 77-93.

DE METS C, GORDON RG \& ROYER JY. Motion between the Indian, Capricorn and Somalian plates since $20 \mathrm{Ma}$ : implications for the timing and magnitude of distributed lithospheric deformation in the equatorial Indian Ocean, Geophysics. J. Int., 2005; 161: 445-468.

GAMAGE SSN, UMINO N, HASEGAWA A \& KIRBY SH. Offshore double-planed shallow seismic zone in the NE Japan forearc region revealed by $\mathrm{sP}$ depth phases recorded by regional networks, Geophys. J. Int. 2009; 178: 195-214.
HASEGAWA A, UMINO $\mathrm{N} \&$ TAKAGI A. Double-planed structure of the deep seismic zone in the northeastern Japan arc, Tectonophysics. 1978; 47: 43-58.

NISHIZAWA A, KANAZAWA T, IWASAKI T $\&$ SHIMAMURA H. Spatial distribution of earthquakes associated with the Pacific plate subduction off northeastern Japan reveled by ocean bottom and land observation, Phys. Earth planet. Inter. 1992; 75: 165-175.

ROYER JY \& CHANG T. Evidence for relative motions between the Indian and Australian plates during the last $20 \mathrm{Myr}$ from plate tectonic reconstructions: Implications for the deformation of the Indo-Australian plate, J. Geophys. Res. 1991; 96: 11,779-11,802.

STAUDER W. Tensional character of earthquake foci beneath the Aleutian trench with relation to sea-floar spreading, J. Geophys. Res. 1968; 73: 7693-7701.

STEIN S \& WIENS DA. Depth determination for shallow teleseismic earthquakes: method and results, Rev. Geophys. 1986; 24: 806-832.

UMINO N \& HASEGAWA A. On the twolayered structure of a deep seismic plane in northeastern Japan arc, J. Seism. Soc. Japan. 1975; 28: 125-139

YOSHII T. A detailed cross-section of the deep seismic zone beneath northeastern Honshu, Japan, Tectonophysics. 1979; 55: 349-360. 